\title{
Johannes Schmidt
}

\section{Die Grundsätze im Sinne der EU-Grundrechtecharta}

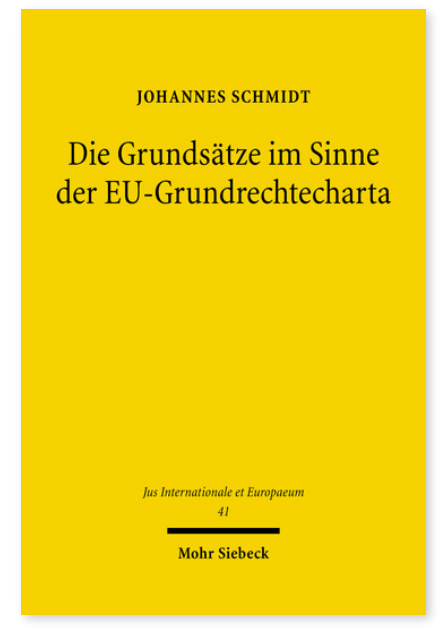

2010. XVII, 264 Seiten. JusIntEu 41

ISBN 978-3-16-151180-6

DOI 10.1628/978-3-16-151180-6

eBook PDF 69,00€

ISBN 978-3-16-150519-5

fadengeheftete Broschur 69,00€
In der EU-Grundrechtecharta wurde mit den »Grundsätzen« eine neue Grundrechts-Kategorie geschaffen. Johannes Schmidt geht den bisher unbeantworteten Fragen nach, welche Rechtswirkungen diese Normen haben und wie mit ihnen umzugehen ist. Für die Analyse der Grundsätze entwickelt er zunächst ein universal gültiges Strukturmodell für Grundrechtsnormen, das im Wesentlichen auf der »Theorie der Grundrechte« von Robert Alexy aufbaut. Dieses Modell erlaubt es, die Rechtswirkungen der Grundsätze detailliert zu beschreiben, was im zweiten Teil der Arbeit geschieht. Ausführlich wird dabei auf die Frage eingegangen, ob sich subjektive Rechte aus den Grundsätzen ableiten lassen. Im letzten Teil stellt der Autor für die Praxis wichtige Leitlinien für den Umgang mit den Grundsätzen auf. Neben der besonders wichtigen Frage der Justiziabilität wird auch eine Einordnung der Chartanormen vorgenommen.

Johannes Schmidt Geboren 1983; Studium der Rechtswissenschaft in Hamburg; 2010 Promotion; derzeit Rechtsreferendar in Hamburg.

\section{Jetzt bestellen:}

https://mohrsiebeck.com/buch/die-grundsaetze-im-sinne-der-eu-grundrechtecharta-9783161511806?no_cache=1 order@mohrsiebeck.com

Telefon: +49 (0)7071-923-17

Telefax: $+49(0) 7071-51104$ 